\title{
A population-based exposure assessment of risk factors associated with gastrointestinal pathogens: a Campylobacter study
}

\author{
L. A. MacRITCHIE ${ }^{1 *}$, C. J. HUNTER ${ }^{2}$ And N. J. C. STRACHAN ${ }^{1}$ \\ ${ }^{1}$ Institute of Biological and Environmental Sciences, School of Biological Sciences, Cruickshank Building, \\ University of Aberdeen, Aberdeen, UK \\ ${ }^{2}$ School of Geography \& Geosciences, University of St Andrews, Irvine Building, St Andrews, UK
}

Received 27 September 2011; Final revision 1 May 2012; Accepted 11 July 2012; first published online 9 August 2012

\section{SUMMARY}

A questionnaire survey was undertaken to determine the exposure of a study population to campylobacteriosis source risk factors (environmental, water, food) and results were stratified by age, population density and deprivation. Data were gathered using an exposure assessment carried out by telephone in the Grampian region of Scotland. Univariate analysis showed that children aged 5-14 years, living in low population density $\left(0-44 \cdot 4\right.$ persons $\left./ \mathrm{km}^{2}\right)$ and affluent areas had elevated exposure to environmental and water risk factors. Multivariate logistic regression analysis revealed that younger age groups and lower population density were significant indicators for most environmental risk factors. The results compared to reported disease incidence in Grampian showed that greater exposure to risk factors does not necessarily coincide with greater disease incidence for age groups, particularly for the $0-4$ years age group. Further research is required to explain the relationship between exposure and disease incidence.

Key words: Campylobacter, epidemiology, gastroenteritis.

\section{INTRODUCTION}

Gastrointestinal (GI) pathogens (e.g. Campylobacter, E. coli O157, Salmonella, Cryptosporidium) are a significant cause of disease in humans and they generate economic loss to society [1-3]. For example, GI infection is estimated to cost the USA $\$ 7 \cdot 3$ billion [4] and England approximately $£ 750$ million per annum [5]. These pathogens cause a range of symptoms from diarrhoea, abdominal pain, fever and vomiting [6-12] to haemolytic-uraemic syndrome (e.g. E. coli O157) [13, 14], Guillian-Barré syndrome (e.g.

* Author for correspondence: Miss L. A. MacRitchie, School of Biological Sciences, Cruickshank Building, St Machar Drive, University of Aberdeen, Aberdeen, AB24 3UU, UK.

(Email: laura.macritchie@abdn.ac.uk)
Campylobacter) [15] and occasionally death (e.g. Campylobacter, Salmonella, E. coli O157, Cryptosporidium) $[10,16,17]$. The number of GI cases is under-reported, with only $1 / 17$ cases of infectious intestinal disease presenting to General Practitioners in England [18]. In the USA, about $1 / 38$ cases of non-bloody diarrhoea and $1 / 20$ of bloody diarrhoea are disclosed [19]. In developed countries, taking into account unreported cases, it is estimated that one third of people are infected each year by foodborne disease [17]. Infection occurs by the transmission of pathogens from animals to humans and can arise via a number of pathways [20]; three primary (foodborne [21], waterborne [22], environmental [23]), and one secondary (person-to-person transmission [17]). 
Campylobacter is the most common bacterial cause of GI disease worldwide [24]. Cases of human campylobacteriosis tend to be sporadic with few identified outbreaks, making it difficult to identify the source of infection in individuals [17]. However, infection is associated with a wide range of pathways which include unpasteurized milk [25], travel, contact with domestic animals and pets [24], eating in restaurants, swimming, barbeques [26] consumption of undercooked poultry [21], drinking water from private supplies [24], and accidental ingestion of contaminated mud [27].

Risk factors denote anything that could be associated with the risk of disease [28]. They can be categorized into either source or population attributable risk factors. Source risk factors are directly associated with the pathway of infection; for example, the environment (contact with farm animals [17]), water exposure (drinking from private water supplies [22, 29]) and food exposure (consumption of contaminated chicken meat [21]). Population attributable risk factors have an indirect association with infection and include age [30], population density [31], and deprivation (e.g. the Carstairs index) [32]. Campylobacter illness has been found to be higher in the $0-4$ years age group [33] and in people living in affluent areas [34].

Epidemiological methods are important for identifying source risk factors of GI pathogens and those individuals at greatest risk, therefore facilitating informed decisions regarding disease prevention [28]. Traditional epidemiological methods used to identify GI pathogen risk factors include case-control studies [24], cohort studies [18, 35], and outbreak investigations [36]. However, these have been based on a sub-population (e.g. representative of an outbreak), and have not therefore determined actual exposure to risk factors across the whole population. An additional method used in epidemiological studies is an exposure assessment, which typically takes the form of a questionnaire. Exposure assessments have been used in previous studies including quantifying the affect of sun exposure resulting in skin cancer [37] and managing food safety risks [38]. Campylobacter studies have used exposure assessments to estimate which sources are the most likely cause of human infection [39]. For example, to assess the importance of three key risk factors a study was performed in Switzerland to estimate the exposure to Campylobacter by age groups [40]. However, the study used previous case-control data to identify the exposures and was not based on a cross-section of the entire population. We believe that the work reported in the present study is the first to investigate exposure to risk factors associated with GI pathogens across the whole population.

This study sought to conduct a population-based exposure assessment to determine the importance of source risk factors stratified by population attributes (age, population density, deprivation). The focus was on Campylobacter because of its high disease burden within the human population. Furthermore, comparison of the exposure assessment results with human disease incidence was conducted to observe whether greater exposure is associated with reported Campylobacter infection.

\section{METHODS}

The study area was the Grampian region (population 528634 ) in northeast Scotland. This area was selected because of its demography and the range of environmental, food and water [e.g. private water supply (PWS)] risk factors to which the population is exposed [41]. The region has residents living across both rural (population density $<200$ persons $/ \mathrm{km}^{2}$ ) [41] and urban areas. In order for the sample data to represent the study population, information was obtained from the 2001 Scottish census [42], including population density, age distribution and deprivation score for each of the 102 postcode sectors (e.g. AB23 8**) in Grampian.

A telephone exposure assessment questionnaire survey $(n=1061)$ was conducted between September 2008 and June 2009 to establish the frequency of exposure to Campylobacter risk factors on a population basis. The study included any person who was resident in Grampian region at the time the survey was conducted and who had a phone number accessible in the online directory. Children were incorporated by asking parents or guardians to respond on behalf of their child if they were aged between 0 and 12 years. Participants were randomly selected by postcode sectors in the phone directory, the phone numbers were recorded in a Microsoft Excel 2003 spreadsheet. It was considered important that participants from all postcode sectors were represented in the study data. The phone numbers were dialled until 10 questionnaires were completed for each postcode sector. It was necessary, due to limited resources, to have only 10 questionnaires per sector completed. The participation rate was calculated as $28 \%$. 
Table 1. Overview of the questionnaire - the questions and response options included in the exposure assessment questionnaire

\begin{tabular}{ll}
\hline \hline Questions & Response options \\
\hline How often do you visit farms or cross fields with cattle, sheep or goats & $1-$ Never \\
in them? & $2-$ Annually \\
How many occasions in a year do you think you handle or touch & $3-$ Monthly \\
orstroke cattle, sheep or goats? & $4-$ Weekly \\
How often do you camp on a field that has recently had cattle, sheep & 5 - Everyday \\
or goats on it? & \\
How often do you touch a live hen or chicken? & \\
How often do you paddle or swim or do any type of water sports on & $1-$ Public chlorinated \\
or in lochs, rivers or the sea in Grampian? & $2-$ Private well or spring \\
How often do you eat chicken or turkey? & $1-$ Never \\
How often do you eat a beefburger? & $2-$ About a quarter of the time \\
What type of water supply do you have? & $3-$ About half of the time \\
Do you eat your beefburger rare? & $4-$ About three quarters of the time \\
\end{tabular}

Questions included participant's age, gender, occupation and postcode to identify the sociodemographic characteristics of the respondent. Questions covering environmental, water and food exposures, with provided response options, were also asked to determine the frequency of exposure to Campylobacter risk factors over an annual period, the overview of the questions can be seen in Table 1. The response options were categorized as not exposed (never) and exposed (annually, monthly, weekly, every day) to quantify the exposure people had to the risk factors. The answers were recorded in SNAP survey software and then exported into Microsoft Excel 2003 for analysis.

Responses were stratified by the population attributes of age, population density and deprivation. The survey data were divided into age groups to reflect the Grampian population and fitted to the age structure of the region $(0-4,5-14,15-64, \geqslant 65$ years) [42]. The population density groups were split so that each contained similar population numbers $(0-45 \cdot 2,45 \cdot 3-249 \cdot 8, \quad 249 \cdot 9-1789 \cdot 7, \quad 1789 \cdot 8-3106 \cdot 4$, $3106 \cdot 5-11970 \cdot 6 \mathrm{~km}^{2}$ ). The Carstairs index was used as a measure of deprivation as it was attainable at postcode sector level and based on the 2001 census. It was originally developed by Carstairs \& Morris in the 1980s based on the 1981 census and used the four census variables of unemployment, overcrowding in homes, car ownership and low social class as indicators of socioeconomic status. As the Carstairs index is based on the census it should provide unbiased results for the resident population [43]. The Carstairs index gives a score from +6 (most deprived) to -6 (least deprived) in Grampian. The deprivation indices were grouped together to avoid producing a sample size that would be too small $(-6$ to $-5,-4$, -3 to $-2,-1$ and 0 to 6$)$.

The study sample collected was found not to correspond to the Grampian population because there was over representation of the elderly and people living in the lowest population density areas. Therefore the original study data were reduced by randomly sampling the data using PopTools in Microsoft Excel 2003. To remove the sample bias, the data were first arranged by age and the oldest age group was selected and shuffled. From this a random number was chosen before the remaining data were combined. Then the data were arranged by population density groups and the lowest population density group was chosen and shuffled. A random number was selected and then reunited with the remaining data. Each population attribute was summed and a binomial confidence calculation performed to compare with the Grampian population. The procedure was performed several 
times until a subsample was found to represent the Grampian population $(n=580)$ which has a margin of error of $<5 \%$ [44].

Univariate analysis involved calculation of odds ratios (OR) [45] with $95 \%$ confidence intervals (CI) using Microsoft Excel 2003 and $P$ values were determined by Fisher's exact test [46] to assess if the different population attribute groups had significantly higher exposure compared to the reference categories ( $\geqslant 65$ years, $\left.3106 \cdot 5-11970 \cdot 6 \mathrm{~km}^{2}, 0-6\right)$. The average annual exposures for each pathway risk factor were stratified by population attribute and calculated. For each response option a frequency of time was assigned (never $=0$, annually $=1$, monthly $=12$, weekly $=52$, every day $=365$ ). To obtain the mean and CI values of the overall frequency of exposure to the risk factors the Monte Carlo method was used with 10000 simulations after the data had been re-sampled using PopTools. The mean was the average number of times people in particular population attribute groups were exposed to the risk factor pathways (see online Supplementary material). PWS consumption data were obtained by calculating the number of glasses of water consumed per day. The $95 \%$ CIs were generated by bootstrapping with 10000 simulations (PopTools version 3.1.1) [47].

Identified Campylobacter cases in Scotland are routinely reported by the clinical diagnostic laboratories. Non-identifiable patient age, postcode aggregated data on Campylobacter cases between 2000 and 2006 were obtained for Grampian. For each case the population density and deprivation score were determined. There was no source risk factor information provided with the cases. Participants' occupation data was used in univariate logistic regression to discover if employment was a significant risk factor. Further analysis was conducted by multivariable logistic regression (Egret ${ }^{\circledR}$, Cytel, USA) to investigate the relationship between the population attributable risk factors and each source risk factor. The logistic regression tested to discover if any significant ORs were produced. Inclusion of multivariate analysis was selected by variables in univariate analysis that had a $P$ value of $<0 \cdot 2$.

\section{RESULTS AND DISCUSSION}

Univariate analysis of the frequency of exposure to the source risk factors (OR) was stratified by the three different population attribute categories: age, population density and the Carstairs index; the results are shown in Figures 1-3, respectively.

The 5-14 years age group (Fig. 1) was found to have the greatest exposure to the majority of source risk factors investigated compared to the $\geqslant 65$ years group. This included visiting farms and crossing fields, handling farm animals, contact with live chickens, contact with fresh water or sea water and consumption of beefburgers. The $\geqslant 65$ years age group had the least exposure (Fig. $1 a-c$ ). Comparing the age-related exposure results with the incidence of Campylobacter disease in Grampian (Fig. 1d), we found the $0-4$ years age group to have the greatest number of cases and the 5-14 years age group the least, indicating that greater exposure does not necessarily result in higher disease incidence. It is not clear why this difference exists and further investigation is required. However, it may be that those aged $0-4$ years are more susceptible to infection because of low immunity or due to behavioural factors (e.g. poor hygiene, with young children particularly prone to putting their hands and toys, etc. into their mouths $[31,48])$. It is unclear why the $5-14$ years age group has the lowest incidence, despite relatively high exposure to source risk factors. This could be due, to some extent, to immunity acquired as age increases [33].

The $\geqslant 65$ years age group was found to have the least exposure to many of the source risk factors, except for consumption of poultry. The reduced exposure to environmental source risk factors could be due to behavioural differences in older people; e.g. mobility or health problems preventing engagement in outdoor pursuits. This finding is in agreement with Campylobacter disease incidence in Grampian which shows elderly people as having lower incidence (Fig. 1d). Furthermore, in England and Wales [49] and Scotland [33] reports of Campylobacter infection also indicate a decline in incidence for those aged $\geqslant 70$ years.

Considering population density as an exposure risk factor (Fig. 2), living in a low-density area was found to be significant for greater exposure to environmental source risk factors (Fig. $2 a$ ). In particular, people living in areas of $0-44 \cdot 4$ persons $/ \mathrm{km}^{2}$ had greater exposure to visiting farms and crossing fields with farm animals present, handling farm animals, contact with live chickens, and use of a PWS. Other source risk factors were not significant for population density. When the OR findings were compared with Campylobacter disease incidence in Grampian, it was found that a higher incidence of cases occurred in the 

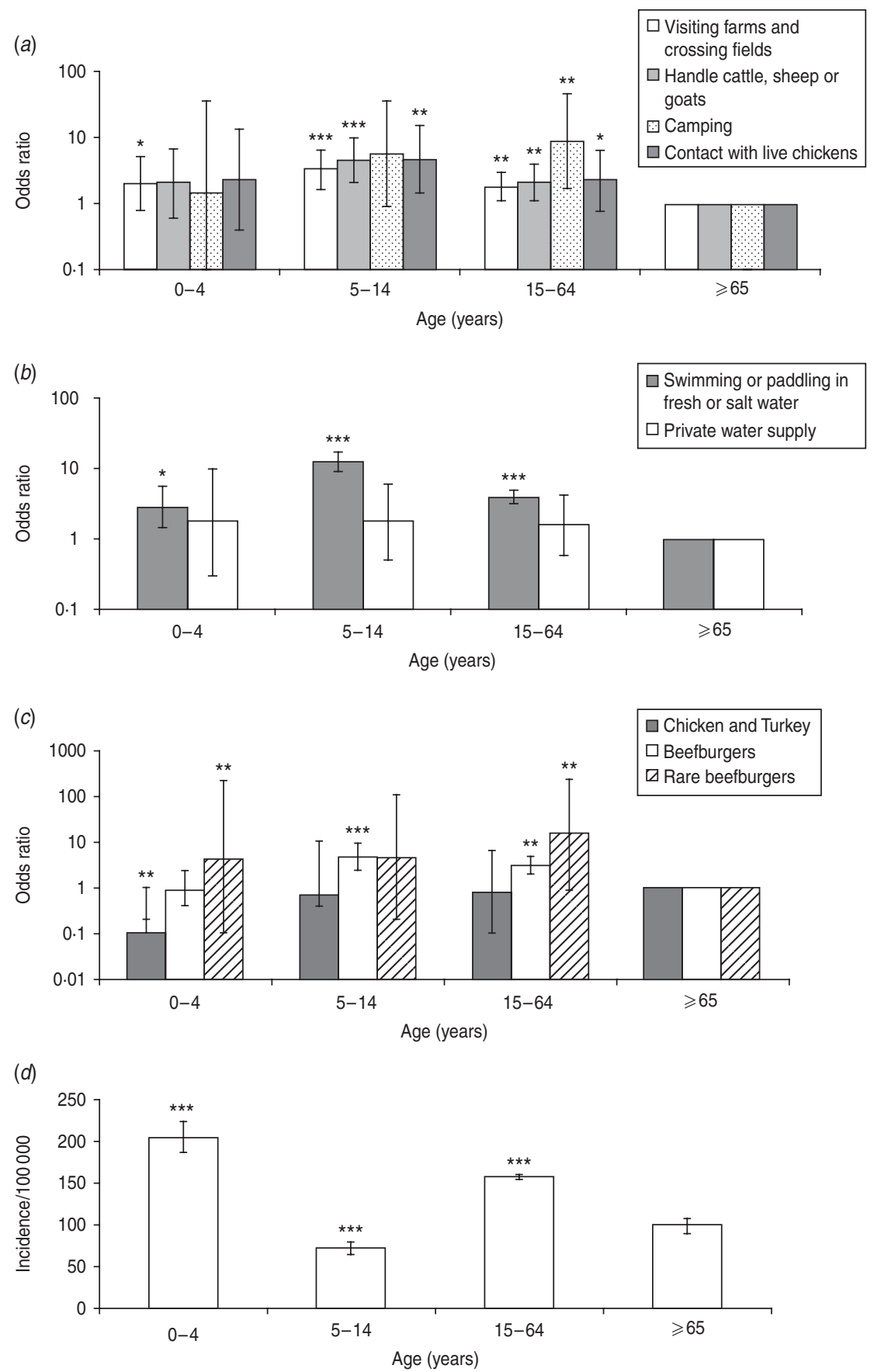

Fig. 1. The odds ratio scores for age group exposures to source risk factors: $(a)$ environmental exposures, $(b)$ water exposures, $(c)$ food exposures, and $(d)$ the incidence of Campylobacter in Grampian. Significant difference between each age group is determined by comparison to the reference age group which is $\geqslant 65$ years $(a-c)$. Significance is denoted by $* P=0 \cdot 05-0 \cdot 01$, $* * P=0 \cdot 01-0 \cdot 001$ and $* * * P<0 \cdot 001$ for all graphs.

sparsely populated areas where there is greater exposure to source risk factors (Fig. 2d), indicating a connection between environmental exposures and disease incidence. A previous study [50] has indicated the importance of residing in rural areas by reporting an association between living in an area with a high ruminant density and Campylobacter incidence.
Water supplies and specifically PWS have been reported to cause Campylobacter infection [51-53]. A large number (12\%) of properties in Grampian have a PWS, which is higher than other Scottish regions. This may explain why exposure to a PWS was shown to be an important risk factor for people living in low population density areas. The findings in this paper 

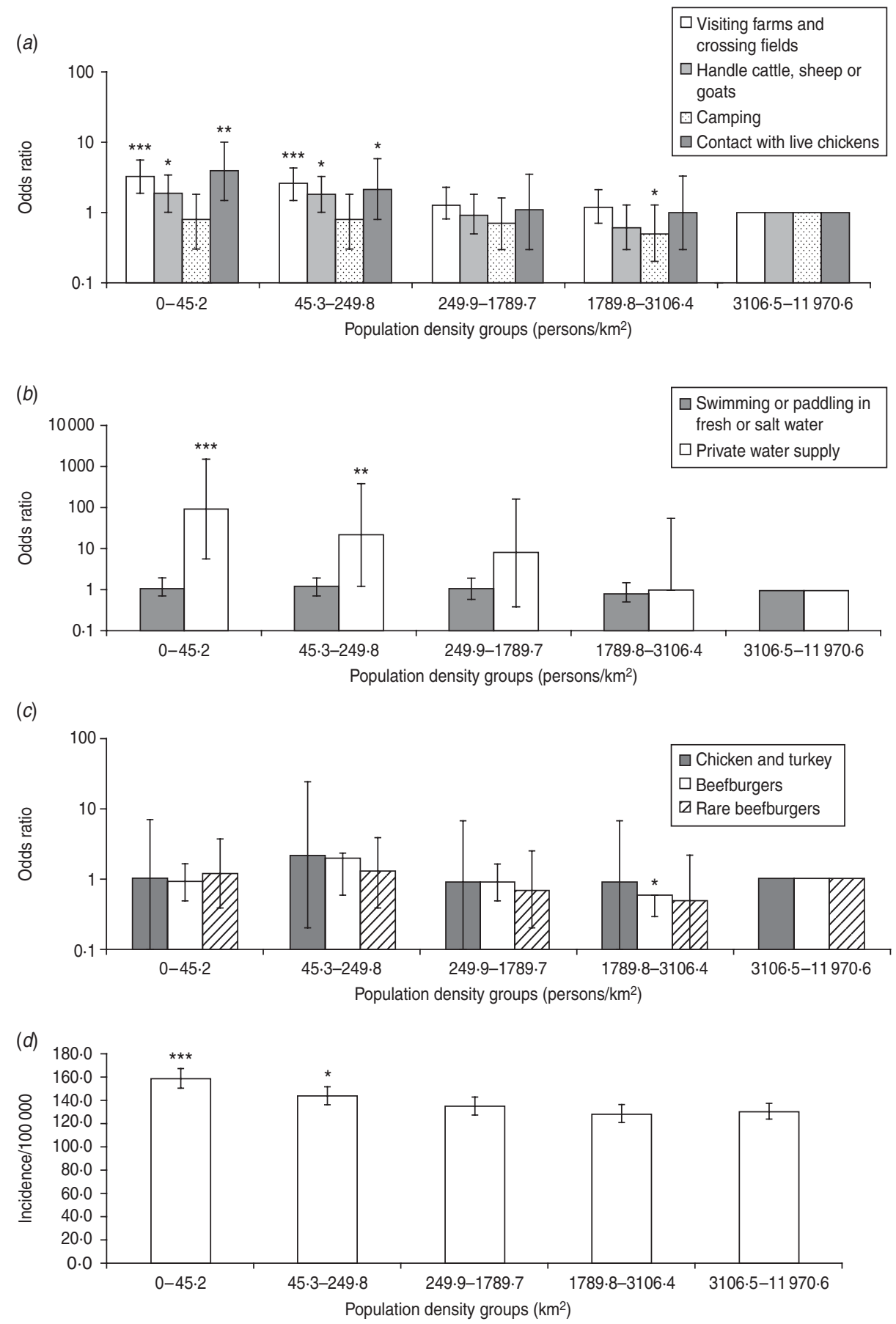

Fig. 2. The odds ratio scores for population density exposure to source risk factors: $(a)$ environmental exposures, $(b)$ water exposures, $(c)$ food exposures, and (d) the incidence of Campylobacter in Grampian. Significant difference between the lowest and highest density groups is determined by comparison to the reference group which is $3110 \cdot 9-11970 \cdot 6 \mathrm{~km}^{2}(a-c)$. Significance is denoted by $* P=0 \cdot 05-0 \cdot 01, * * P=0 \cdot 01-0 \cdot 001$ and $* * * P<0 \cdot 001$ for all graphs.

suggest that a possible target for public health protection would be people living in rural areas and particularly those with a PWS.

Those living in affluent areas (Carstairs index -6 to -4) (Fig. 3) had greater exposure to Campylobacter source risk factors for visiting farms and crossing fields, handling farm animals, contact with live chickens, contact with fresh water and salt water, and use of a PWS (Fig. $3 a-c$ ). Again, this accords with Campylobacter disease incidence in Grampian 

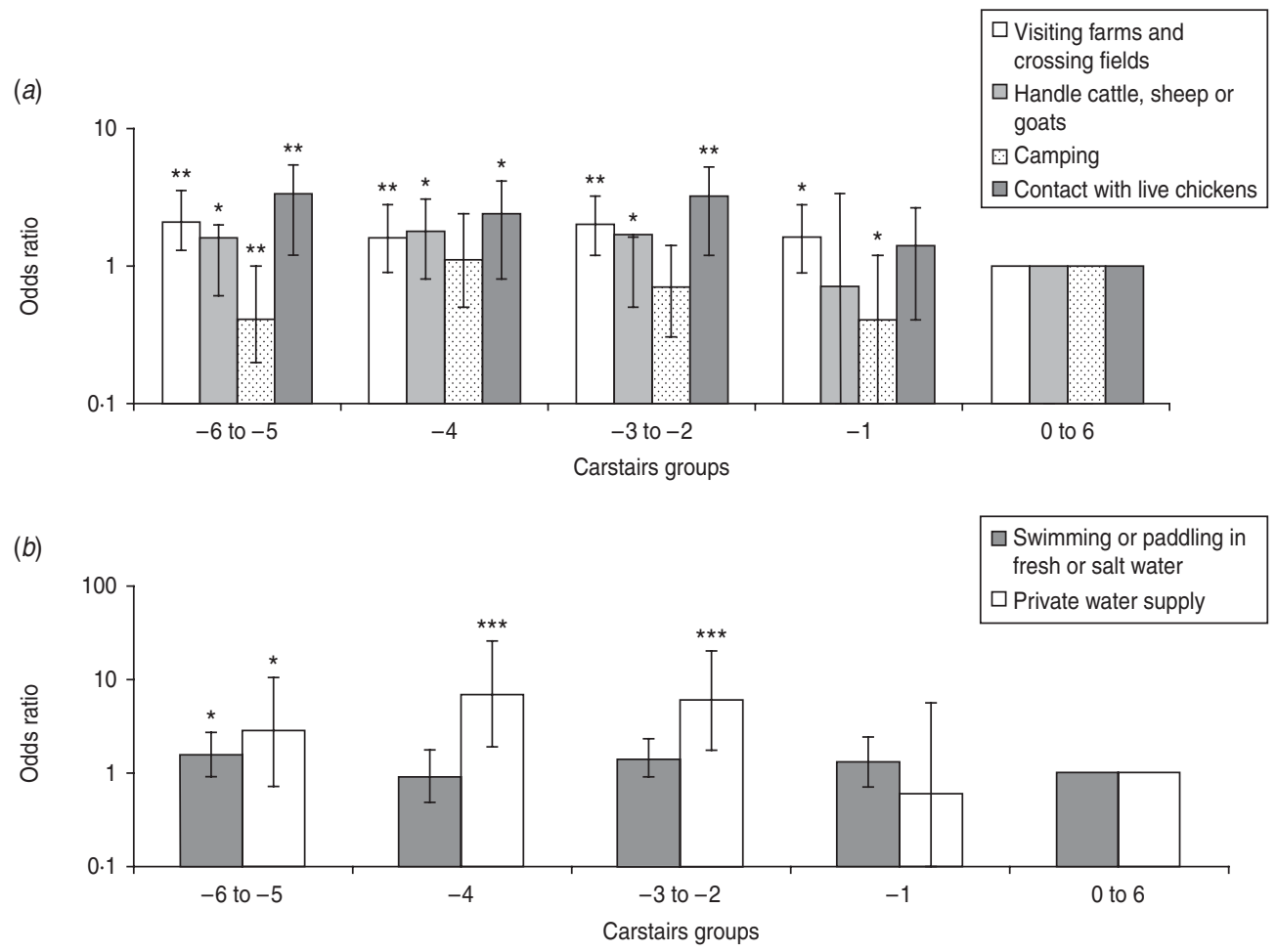

(c)
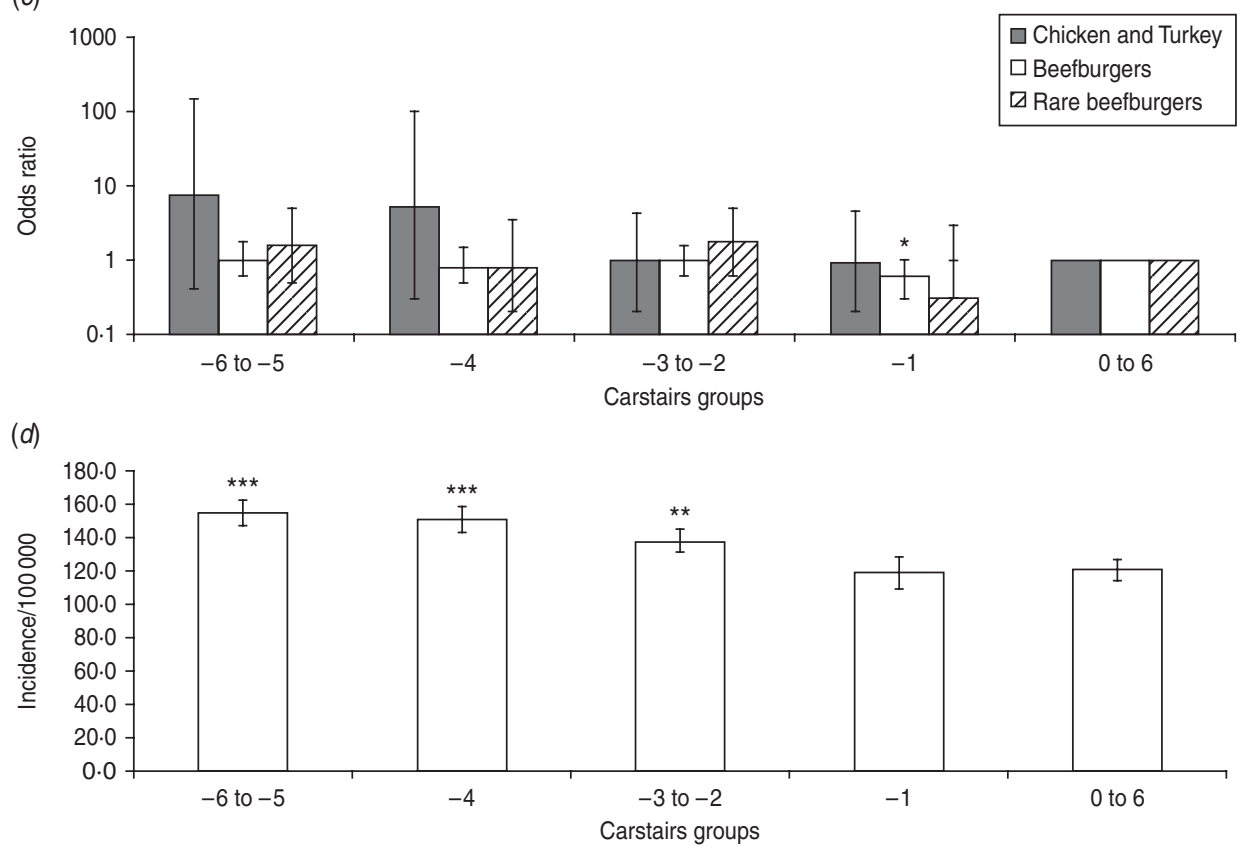

Fig. 3. The odds ratio scores for Carstairs index exposure to source risk factors: $(a)$ environmental exposure, $(b)$ water exposure, $(c)$ food exposure, and $(d)$ the incidence of Campylobacter in Grampian. Significant difference between affluent and deprived areas is determined by comparison to the reference Carstairs group which is $0-6(a-c)$. Significance is denoted by $* P=0 \cdot 05-0 \cdot 01, * * P=0 \cdot 01-0 \cdot 001$ and $* * * P<0 \cdot 001$ for all graphs.

(Fig. 3d) [34]. The result may be explained by the behaviour of people living in affluent areas; e.g. they may be more likely to report illness when they are infected [54]. Further, this study (data not presented) observed that for employed participants only exposure to beefburgers was a significant source risk factor. The finding implies that employed people would more frequently eat beefburgers than 
Table 2. Results of multivariate logistic regression analysis - specific source regressed against population risk factors

\begin{tabular}{|c|c|c|c|}
\hline \multirow[b]{2}{*}{ Source risk factors } & \multicolumn{3}{|c|}{ Population risk factors } \\
\hline & Age $\mathrm{OR} \dagger(95 \% \mathrm{CI})$ & $\begin{array}{l}\text { Population density } \\
\text { OR } \div(95 \% \text { CI })\end{array}$ & $\begin{array}{l}\text { Deprivation } \\
\text { OR§ }(95 \% \mathrm{CI})\end{array}$ \\
\hline Visiting farms, crossing fields & $0 \cdot 70(0.53-0.91)^{* *}$ & $0.74(0.65-0.85)^{* * *}$ & $1 \cdot 00(0 \cdot 87-1 \cdot 15)$ \\
\hline Handling farm animals & $0 \cdot 67(0 \cdot 50-0 \cdot 89)^{* *}$ & $0 \cdot 81(0 \cdot 69-0 \cdot 95)^{*}$ & $0 \cdot 97(0 \cdot 82-1 \cdot 14)$ \\
\hline Contact with live chickens & $0 \cdot 70(0 \cdot 46-1 \cdot 06)$ & $0.71(0.55-0.90)^{* *}$ & $0.92(0 \cdot 72-1 \cdot 18)$ \\
\hline $\begin{array}{l}\text { Paddling or swimming in fresh } \\
\text { or salt water }\end{array}$ & $0.51(0 \cdot 39-0 \cdot 68)^{* * *}$ & - & - \\
\hline Private water supply & - & $0 \cdot 21(0 \cdot 13-0 \cdot 34)^{* * *}$ & $1 \cdot 23(0 \cdot 90-1 \cdot 67)$ \\
\hline Chicken and turkey & - & - & $0.67(0.47-0.95)^{*}$ \\
\hline Beefburgers & $0.72(0.55-0.94)^{*}$ & - & - \\
\hline
\end{tabular}

OR, Odds ratio; CI, confidence interval.

-, No data due to univariate results with $P$ value of $<0 \cdot 2$ excluded from multivariate analysis.

$\dagger \mathrm{OR}<1$ for age indicates increasing exposure with younger age.

$\ddagger$ OR $<1$ for population density indicates increasing exposure with lower population density.

$\S \mathrm{OR}<1$ for deprivation indicates increasing exposure with increasing affluence.

* $P=0 \cdot 05-0 \cdot 01$, ** $P=0.01-0.001$, *** $P>0 \cdot 001$.

'unemployed people' (this includes, unemployed, students and the retired). The exposure to beefburgers may strengthen the argument that diet is an important risk factor for deprivation and campylobacteriosis (see online Supplementary material). Frequently eating in restaurants and the consumption of high-risk foods such as rare or undercooked meats and imported fresh produce have also been suggested as possible explanations for differences between Campylobacter incidence in deprived and affluent areas $[32,54]$.

Travel abroad is an important risk factor that should be taken into consideration as it may account for $20 \%$ of Campylobacter cases in the UK [55]. Frequent foreign travel has been associated with affluence and, therefore, it could be a risk factor that contributes to the increased incidence in more affluent areas. By contrast information on foreign travel [56] shows that the $0-4$ and $\geqslant 65$ years age groups infrequently take trips abroad. This indicates that the source of infection for those aged $0-4$ years is of indigenous origin and that foreign travel is not an important cause of infection in the $\geqslant 65$ years age group.

Thinking more broadly about GI pathogen risk, the approach and findings adopted in this study can be applied to other GI pathogens, such as E. coli O157, Salmonella and Cryptosporidium, as these have a number of similar source and population attribute risk factors [17, 29, 57]. It is interesting to note, for example, that the age-related disease incidences for E. coli O157 [58], Salmonella [59] and Cryptosporidium [29] indicate a higher number of cases in the $0-4$ years age group, which does not conform to the findings in this study of greatest exposure in the 5-14 years age group. By contrast our findings of greater exposure for those living in low population density areas are consistent with E. coli O157 disease incidence, as twice as many cases have been reported for rural areas compared to urban areas [60]. Similarly, it has been reported that Cryptosporidium has a higher incidence in rural areas [29]. The finding of greater exposure in affluent areas is also consistent with studies of other bacterial GI infections which indicate a relationship between increasing socioeconomic status and increasing risk of infection; for example, in relation to Shigella and Salmonella Enteritidis [32]. To understand further the relationship between the risk factors, additional investigations are required. To achieve this multivariate logistic regression was employed.

The multivariate logistic regression analysis (Table 2) showed that the elderly and those living in highly populated areas had significantly less exposure to visiting farms and crossing fields, and handling farm animals. Contact with live chickens and those with a PWS were found to be significant for people living in rural areas, while consumption of chicken and turkey were significant for those living in affluent areas. It was established that the younger age group 
had higher exposure to beefburgers and paddling or swimming in fresh water or salt water compared to other population groups. The multivariate analysis reduced the number of significant risk factors compared to the univariate methodology. For example visiting farms and handling farm animals were also significant for those living in affluent areas. Children (5-14 years) and people living in affluent areas were additionally significant for exposure to contact with live chickens. Those with a PWS were also significant for people living in affluent areas and there were no significant population attributes for consumption of chicken and turkey. Finally, exposure to source risk factors associated with affluence were no longer significant where they previously were in the univariate results (except for chicken and turkey consumption).

This study had a number of limitations including sample bias, which was resolved, and not taking into account under-reporting when the incidence levels for Campylobacter in Grampian were calculated (this may vary by socioeconomic status and age). Additional bias may have been introduced by people who were more likely to be at home the time of day the survey calls were made and the type of person who would be more willing to participate in the study.

Campylobacter incidence exhibits seasonality in temperate countries and peaks in May in the UK [61], this may in part be due to increased environmental risk at this time of year [62]. In the present study, data were collected on the total average exposure across a whole year, so it was not possible to extract seasonal differences although these are likely to occur. A further extension of the approaches described here could be in ecological studies. For example, in these types of study (e.g. Friesema et al. [63]) spatial regression methods are used to correlate human disease cases with risk factors such as animal densities. The data collected in the present paper includes frequency of exposure which is likely to be a better indicator of risk.

In conclusion, a questionnaire-based exposure assessment was used to determine the frequency of exposure of a population to source and population attributable risk factors (we believe for the first time). This study suggests elevated exposures to source risk factors in Grampian associated with Campylobacter were for older children (5-14 years), people living in low population density areas $\left(0-44 \cdot 4\right.$ persons $\left./ \mathrm{km}^{2}\right)$, and those living in affluent areas (Carstairs index -6 to -4$)$. Multivariate analysis revealed that younger age and living in lower population density areas were significant indicators for most environmental source risk factors. These findings may be used to inform public health protection policy by assisting in targeting the people who are potentially at greater risk of infection. However, our comparison of exposure assessment findings compared with Campylobacter disease incidence suggests that greater exposure does not always result in greater incidence. This was particularly evident for the $0-4$ years age group and further research is required to establish the mechanisms of Campylobacter infection in this group. It is possible that behavioural factors in young children such as poor hygiene (hand to mouth behaviour) and decreased immunity are important. Hence, improved understanding of both behaviour and immunity are required in order for public health to develop strategies to reduce the burden of these GI pathogens.

\section{SUPPLEMENTARY MATERIAL}

For supplementary material accompanying this paper visit http://dx.doi.org/10.1017/S0950268812001641.

\section{ACKNOWLEDGEMENTS}

This research was undertaken by a Rural Economy and Land Use (RELU) linked studentship funded by the Economic and Social Research Council, entitled 'Campylobacteriosis: elucidating the disease burden, risk perception and costs to rural communities and their families' (RES 229-25-0012). RELU is jointly funded by the Economic and Social Research Council, the Biotechnology and Biological Sciences Research Council and the National Environment Research Council, with additional support from Department for Environment, Food and Rural Affairs and the Scottish Government. We thank the participants of this study for their contribution, the Grampian Public Health Team for providing the Campylobacter incidence data, Rachel Cartwright for her involvement with the telephone exposure assessment and Ovidiu Rotariu for assisting with the Campylobacter confirmed case data.

\section{DECLARATION OF INTEREST}

None. 


\section{REFERENCES}

1. Morens DM, Folkers GK, Fauci AS. The challenge of emerging and re-emerging infectious diseases. Nature 2004; 430: 242-249.

2. Walsh AL, Morgan D. Identifying hazards, assessing the risks. Veterinary Record 2005; 157: 684-687.

3. Shaheen NJ, et al. The burden of gastrointestinal and liver diseases, 2006. American Journal of Gastroenterology 2006; 101: 2128-2138.

4. Sandler RS, et al. The burden of selected digestive diseases in the United States. Gastroenterology 2002; 122: 1500-1511.

5. Food Standards Agency. A report of the study of infectious intestinal disease in England. London: HMSO, 2000.

6. Allos BM. Campylobacter jejuni infections: update on emerging issues and trends. Clinical Infectious Diseases 2001; 32: 1201-1206.

7. Butzler JP. Campylobacter, from obscurity to celebrity. Clinical Microbiology and Infection 2004; 10: 868876.

8. Mathieu E, et al. Epidemiologic and environmental investigation of a recreational water outbreak caused by two genotypes of Cryptosporidium parvum in Ohio in 2000. American Journal of Tropical Medicine and Hygiene 2004; 71 : 582-589.

9. Chase-Topping M, et al. Super-shedding and the link between human infection and livestock carriage of Escherichia coli O157. Nature Reviews Microbiology 2008; 6: 904-912.

10. Defra. Zoonoses report United Kingdom 2008. 2010.

11. Litrup E, et al. DNA microarray analysis of Salmonella serotype Typhimurium strains causing different symptoms of disease. BMC Microbiology 2010; 10: 96.

12. Ng JSY, et al. Molecular characterisation of Cryptosporidium outbreaks in Western and South Australia. Experimental Parasitology 2010 ; 125 : 325-328.

13. Crump JA, et al. An outbreak of Escherichia coli O157:H7 infections among visitors to a dairy farm. New England Journal of Medicine 2002; 347 : 555-560.

14. Solecki O, et al. E. coli O157 from sheep in northeast Scotland: prevalence, concentration shed, and molecular characterization by multilocus variable tandem repeat analysis. Foodborne Pathogens and Disease 2009; 6: 849-854.

15. Yan SS, et al. Campylobacter infection and Guillain-Barré syndrome: public health concerns from a microbial food safety perspective. Clinical and Applied Immunology Reviews 2005; 5: 285-305.

16. Havelaar AH, et al. Effectiveness and efficiency of controlling Campylobacter on broiler chicken meat. Risk Analysis 2007; 27: 831-844.

17. Schlundt J, et al. Emerging food-borne zoonoses. Revue Scientifique et Technique de l'Office International des Epizooties 2004; 23: 513-533.

18. Tam CC, et al. Longitudinal study of infectious intestinal disease in the UK (IID2 study): incidence in the community and presenting to general practice. Gut 2012; 61: 69-77.
19. Mead PS, et al. Food-related illness and death in the United States. Emerging Infectious Diseases 1999; 5: 607-625.

20. Stirling $\mathbf{J}$, et $\boldsymbol{a l}$. Zoonoses associated with petting farms and open zoos. Vector-Borne and Zoonotic Diseases 2008; 8: 85-92.

21. Gormley FJ, et al. Has retail chicken played a role in the decline of human campylobacteriosis? Applied and Environmental Microbiology 2008; 74: 383-390.

22. Pelly $\mathbf{H}$, et al. A large outbreak of cryptosporidiosis in western Ireland linked to public water supply: a preliminary report. Eurosurveillance 2007; 12.

23. Howie $\mathbf{H}$, et al. Investigation of an outbreak of Escherichia coli $\mathrm{O} 157$ infection caused by environmental exposure at a scout camp. Epidemiology and Infection $2003 ; 131$ : 1063-1069.

24. Neimann J, et al. A case-control study of risk factors for sporadic Campylobacter infections in Denmark. Epidemiology and Infection 2003; 130: 353-366.

25. Danis K, et al. Risk factors for sporadic campylobacter infection: an all-Ireland case-control study. Eurosurveillance 2009; 14: 12-19.

26. Doorduyn Y, et al. Risk factors for indigenous Campylobacter jejuni and Campylobacter coli infections in the Netherlands: a case-control study. Epidemiology and Infection 2010; 138: 1391-1404.

27. Stuart TL, et al. Campylobacteriosis outbreak associated with ingestion of mud during a mountain bike race. Epidemiology and Infection 2010; 138: 1695-1703.

28. Giesecke J. Modern Infectious Disease Epidemiology, 2nd edn. London: Arnold, 2002.

29. Lake IR, et al. Case-control study of environmental and social factors influencing cryptosporidiosis. European Journal of Epidemiology 2007; 22: 805-811.

30. Olowokure B, et al. Deprivation and hospital admission for infectious intestinal diseases. Lancet 1999; 353: 807-808

31. Ethelberg S, et al. Spatial distribution and registrybased case-control analysis of Campylobacter infections in Denmark, 1991-2001. American Journal of Epidemiology 2005; 162: 1008-1015.

32. Simonsen J, Frisch M, Ethelberg S. Socioeconomic risk factors for bacterial gastrointestinal infections. Epidemiology 2008; 19: 282-290.

33. Miller G, et al. Does age acquired immunity confer selective protection to common serotypes of Campylobacter jejuni? BioMed Central 2005; 5: 66-70.

34. Bessell PR, et al. Geographic determinants of reported human Campylobacter infections in Scotland. BMC Public Health 2010; 10: 423.

35. Dale K, et al. Sporadic gastroenteritis and recreational swimming in a longitudinal community cohort study in Melbourne, Australia. American Journal of Epidemiology 2009; 170: 1469-1477.

36. Rimhanen-Finne $\mathbf{R}$, et al. Contaminated water caused the first outbreak of giardiasis in Finland, 2007: a descriptive study. Scandinavian Journal of Infectious Diseases 2010; 42: 613-619. 
37. Karagas MR, et al. Measures of cumulative exposure from a standardized sun exposure history questionnaire: a comparison with histologic assessment of solar skin damage. American Journal of Epidemiology 2007; 165: 719-726.

38. Lammerding AM, Fazil A. Hazard identification and exposure assessment for microbial food safety risk assessment. International Journal of Food Microbiology 2000; 58: 147-157.

39. Evers EG, et al. Campylobacter source attribution by exposure assessment. International Journal of Risk Assessment and Management 2008; 8: 174-190.

40. Buettner S, et al. Risk attribution of Campylobacter infection by age group using exposure modelling. Epidemiology and Infection 2010; 138: 1748-1761.

41. Strachan NJC, et al. Attribution of Campylobacter infection in northeast Scotland to specific sources using multilocus sequence typing (MLST). Journal of Infectious Diseases 2009; 199: 1205-1208.

42. SCROL. Scotland's Census Results OnLine. 2001 Scottish census (http://www.scrol.gov.uk/). Accessed July 2010.

43. Morgan O, Baker A. Measuring deprivation in England and Wales using 2001 Carstairs scores. Health Statistics Quarterly 2006; 31: 28-33.

44. Raosoft. Sample size calculator (http://www.raosoft. com/samplesize.html). Accessed 18 January 2012.

45. Bland JM, Altman DG. The odds ratio. British Medical Journal 1999; 320: 1468.

46. SISA. Two by two table analysis (http://www. quantitativeskills.com/sisa/statistics/twoby2.htm). Accessed June, 2010.

47. PopTools. (www.cse.csiro.au/poptools/). Accessed July 2010.

48. Snedeker KG, et al. Primary and secondary cases in Escherichia coli $\mathrm{O} 157$ outbreaks: a statistical analysis. BMC Infectious Diseases 2009; 9.

49. Gillespie IA, et al. Demographic determinants for Campylobacter infection in England and Wales: implications for future epidemiological studies. Epidemiology and Infection 2008; 136: 1717-1725.

50. Nygard K, et al. Association between environmental risk factors and campylobacter infections in Sweden. Epidemiology and Infection 2004; 132: 317-325.

51. Said B, et al. Outbreaks of infectious disease associated with private drinking water supplies in England and
Wales 1970-2000. Epidemiology and Infection 2003; 130: 469-479.

52. Karagiannis I, et al. A waterborne Campylobacter jejuni outbreak on a Greek island. Epidemiology and Infection 2010; 138: 1726-1734.

53. Richardson G, et al. A community outbreak of Campylobacter jejuni infection from a chlorinated public water supply. Epidemiology and Infection 2007; 135: 1151-1158.

54. Hall GV, et al. Frequency of infectious gastrointestinal illness in Australia, 2002: regional, seasonal and demographic variation. Epidemiology and Infection 2006; 134: 111-118.

55. Charlett A, et al. Foreign and domestic travel and the risk of Campylobacter infection: results from a population-based sentinel surveillance scheme. Journal of Travel Medicine 2003; 10: 136-138.

56. Strachan NJC, et al. Elucidating the seasonality of human Campylobacter infections. In: Szymanski C, Gaynor E, eds. 16th International Workshop on Campylobacter, Helicobacter and Related Organisms, Vancouver edn. Vancouver: Campylobacter, Helicobacter and Related Organisms, 2011, pp. 113114.

57. Bruce-Grey-Owen Sound Health Unit. The investigative report of the Walkerton outbreak of waterborne gastroenteritis, 2000.

58. Locking M, et al. VTEC in Scotland 2004: enhanced surveillance and reference laboratory data. HPS Weekly Report 2006; 39: 290-295.

59. Browning LM, et al. Salmonella in Scotland, 2005. HPS Weekly Report 2007; 41 : 133-138.

60. Strachan NJC, et al. Escherichia coli O157: burger bug or environmental pathogen? International Journal of Food Microbiology 2006; 112: 129-137.

61. Sari Kovats R, et al. Climate variability and campylobacter infection: an international study. International Journal of Biometeorology 2005; 49: 207-214.

62. Sopwith W, et al. Identification of potential environmentally adapted Campylobacter jejuni strain, United Kingdom. Emerging Infectious Diseases 2008; 14: 1769-1773.

63. Friesema IHM, et al. Geographical association between livestock density and human Shiga toxin-producing Escherichia coli O157 infections. Epidemiology and Infection 2011; 139: 1081-1087. 